\title{
Ehrlichia monocítica humana: primer reporte de caso pediátrico en Colombia
}

\author{
Human monocytic ehrlichiosis: first report of a pediatric case in Colombia
}

\author{
Alixandra De la Espriella Pérez,* Andrea Victoria Restrepo Gouzi, ${ }^{\ddagger}$ \\ Mónica Rosa Trujillo Honeysberg, ${ }^{\ddagger}$ David Alejandro Calle Echeverri ${ }^{\S}$ \\ * Fellow de primer año de Infectología Pediátrica, Universidad CES. Medellín, Colombia. \\ ‡ Pediatra, Especialista en Enfermedades Infecciosas, Hospital Pablo Tobón Uribe. Medellín, Colombia. \\ ${ }^{\S}$ Bacteriólogo. Msc. Med. Instituto Colombiano de Medicina Tropical (ICMT), Centro Veterinario, Universidad CES. Medellín, Colombia.
}

\section{RESUMEN}

La erliquiosis es una zoonosis, trasmitida por garrapatas, de incidencia desconocida en Colombia, con un amplio espectro de manifestaciones clínicas, muy similares a las que se presentan en otras infecciones, lo cual dificulta su diagnóstico. Presentamos el caso de una adolescente con fiebre, cefalea, náuseas, brote generalizado, epistaxis, trombocitopenia, leucopenia y meningitis, en quien se confirmó erliquiosis a través de reacción en cadena de polimerasa (PCR) en sangre total. La sospecha clínica basada en la sintomatología y el antecedente de contacto con garrapatas y perros enfermos fueron claves para el inicio del tratamiento empírico temprano y permitieron la curación de la paciente. La descripción de este caso pretende hacer más visible esta enfermedad con el objetivo de evitar retrasos en el diagnóstico y el tratamiento que pueden llevar a resultados adversos, incluyendo la muerte.

Palabras clave: Ehrlichia, erliquiosis humana, zoonosis, Anaplasma, niños.

\section{INTRODUCCIÓN}

La erliquiosis humana es una zoonosis producida por Ehrlichia chaffeensis, una bacteria intracelular obligada trasmitida por garrapatas. Es una enfermedad febril aguda emergente que debería diagnosticarse con mayor frecuencia debido a que los reservorios animales y los vectores han incrementado y a que los humanos habitan, a menudo, regiones donde la población de estos reservorios y de garrapatas es

Financiamiento: Ninguno.

Conflicto de intereses: Ninguno.

Rev Latin Infect Pediatr. 2021; 34 (1): 41-47

\section{ABSTRACT}

Ehrlichiosis is a zoonosis, transmitted by ticks, of unknown incidence in Colombia, with a wide spectrum of clinical manifestations, remarkably similar to those that occur in other infections, which makes its diagnosis difficult. We present the case of a girl with fever, headache, nausea, generalized rash, epistaxis, thrombocytopenia, leukopenia, and meningitis, in whom ehrlichiosis was confirmed through polymerase chain reaction $(P C R)$ in whole blood. The clinical suspicion based on the symptoms and the history of contact with ticks and sick dogs were key to the initiation of early empirical treatment and allowed the patient to heal. The description of this case aims to make this disease more visible to avoid delays in diagnosis and treatment that can lead to adverse outcomes, including death.

Keywords: Ehrlichia, human ehrlichiosis, zoonosis, Anaplasma, children.

alta. ${ }^{1}$ Las personas que sufren erliquiosis presentan un espectro amplio de manifestaciones desde síntomas inespecíficos que pueden pasar desapercibidos hasta presentar un deterioro progresivo con compromiso multiorgánico. ${ }^{2}$ Estos pacientes se presentan con fiebre, cefalea, mialgias y artralgias; puede haber brote, especialmente en niños y síntomas gastrointestinales. También pueden desarrollar meningitis o meningoencefalitis. Las alteraciones en las pruebas de laboratorio incluyen pancitopenia

Citar como: De la Espriella PA, Restrepo GAV, Trujillo HMR, Calle EDA. Ehrlichia monocítica humana: primer reporte de caso pediátrico en Colombia. Rev Latin Infect Pediatr. 2021; 34 (1): 41-47. https://dx.doi. org/10.35366/99827

www.medigraphic.com/infectologiapediatrica 
y elevación de enzimas hepáticas. El diagnóstico siempre se debe considerar en casos febriles con los hallazgos mencionados y con historia de contacto con perros infestados por garrapatas. El tratamiento se debe iniciar de forma empírica para evitar complicaciones, incluyendo la muerte.

Se describe un caso de una adolescente con antecedente de contacto con perros enfermos, infestados con garrapatas, quien presentó un cuadro grave de erliquiosis con meningitis.

\section{CASO CLÍNICO}

Adolescente de 12 años, sexo femenino, con nueve días de fiebre de 38 grados, dolor retroocular, cefalea intensa, náuseas, dolor abdominal, astenia y adinamia; a las 48 horas de iniciada la enfermedad manifiesta epistaxis, artralgias, brote maculopapular eritematoso no pruriginoso y dolor pleurítico, consultó al servicio de urgencias en un primer nivel de atención donde realizan paraclínicos en los cuales evidencian bicitopenia: hemoglobina: 12.9 $\mathrm{g} / \mathrm{dL}$, hematocrito: $35.2 \%$, leucocitos: $1,900 / \mathrm{mm}^{3}$, neutrófilos: $62 \%$, linfocitos: $33 \%$, plaquetas: $97,200 /$ $\mathrm{mm}^{3}$ y compromiso de la función hepática AST: 58 U/L, ALT: $65 \mathrm{U} / \mathrm{L}$. Por sospecha de dengue grave y persistencia de la fiebre remiten a nuestra institución.

La paciente tenía antecedente epidemiológico de habitar en zona rural del centro occidente de Colombia y convivir con perros que habían estado infestados de garrapatas, presentaban epistaxis y trombocitopenia. Algunos habían muerto por sangrado y anemia.

A la revisión física se describe una paciente en regulares condiciones generales, decaída, álgida, con tensión arterial de 120/56 mmHg, frecuencia cardiaca de 110 latidos $\times$ minuto, temperatura de 38.5 grados, frecuencia respiratoria de 14 respiraciones $\times$ minuto, inyección conjuntival bilateral sin secreción, dolor abdominal de predominio en epigastrio, brote maculopapular generalizado que respetaba cara, palmas y plantas (Figura 1). Al ingreso presentaba pancitopenia e hiponatremia: hemoglobina 10.9 $\mathrm{g} / \mathrm{L}$, hematocrito: $30.3 \%$, leucocitos $2,200 / \mathrm{mm}^{3}$, neutrófilos: $1,496 / \mathrm{mm}^{3}$, linfocitos: $704 / \mathrm{mm}^{3}$, plaquetas 110,000/mm ${ }^{3}$ y sodio: $133 \mathrm{mmol} / \mathrm{L}$ (Tabla 1), por sospecha de Rickettsiosis vs erliquiosis vs leptospirosis se inició manejo con doxiciclina por vía oral a dosis de $2.2 \mathrm{mg} / \mathrm{kg} /$ día y ceftriaxona intravenosa a $100 \mathrm{mg} /$ $\mathrm{kg} /$ día. Se solicitaron varios exámenes para aclarar la etiología, entre éstos, serología para dengue:
IgM (inmunoglobulina $\mathrm{M}$ ): negativa, IgG: positiva, antígeno NS1: negativo, también se descartó malaria con tres gotas gruesas negativas. Se estudió para Rickettsiosis con medición de anticuerpos por técnica de inmunofluorescencia indirecta (IFI) en fase aguda y de convalecencia negativas. Se realizó estudio en busca de leptospirosis con serología: IgM e IgG negativas, PCR en LCR (líquido cefalorraquídeo) negativa y cultivo de orina negativo; también se descartaron otras enfermedades de etiología viral, entre ellas, infecciones por citomegalovirus y virus de Epstein-Barr por estudios serológicos que fueron negativos (Tabla 1). Debido al antecedente de habitar con perros infestados con garrapatas y que estaban enfermos, se inició estudio para erliquiosis incluyendo reacción en cadena de polimerasa (PCR) para Ehrlichia spp. en sangre, la cual fue positiva; en extendido de sangre periférica con tinción de Wright se buscaron mórulas de Ehrlichia spp., pero no se encontraron. En el día 2 de hospitalización presentó síntomas neurológicos: cefalea, fotofobia, tinnitus, diplopía y rigidez de nuca terminal, se hizo punción lumbar la cual confirmó una meningitis aséptica (con glucosa disminuida, proteínas elevadas y leucorraquia a expensas de linfocitos (Tabla 1). Previamente se realizó una resonancia magnética (RMN) cerebral cuyo reporte por radiología infantil fue normal. La ceftriaxona se suspendió al día siete y recibió 14 días de doxiciclina oral por presentar compromiso meníngeo, tuvo evolución satisfactoria, la fiebre mejoró a los tres días de haber iniciado el tratamiento y los síntomas neurológicos mejoraron progresivamente hasta su desaparición. Se dio de alta a los siete días de hospitalización, en buenas condiciones y sin secuelas neurológicas.

La prueba molecular para diagnóstico de Ehrlichia spp se realizó por amplificación enzimática de ADN para la detección cualitativa de patógenos. Se partió

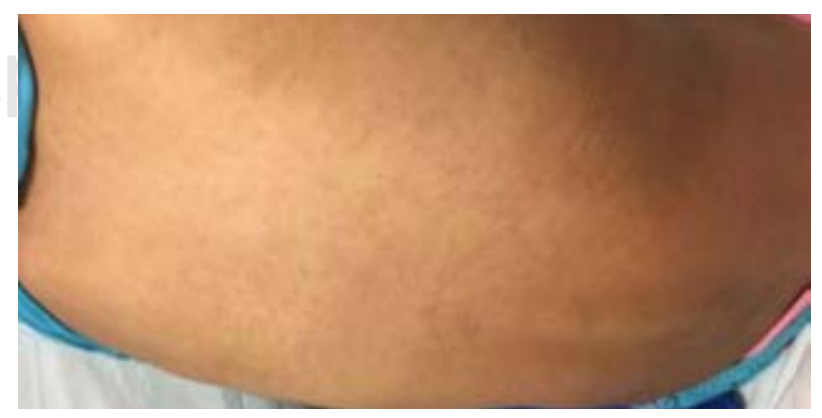

Figura 1: Lesiones en piel. 
Rev Latin Infect Pediatr. 2021; 34 (1): 41-47

\section{Tabla 1: Seguimiento de paraclínicos.}

\begin{tabular}{|c|c|c|c|c|}
\hline \multirow[b]{2}{*}{ Días de la enfermedad } & \multicolumn{4}{|c|}{ Día } \\
\hline & 1 & 7 & 9 & 11 \\
\hline Hemoglobina (g/L) & 12.9 & 10.2 & 10.9 & 10.6 \\
\hline Hematocrito (\%) & 35.2 & 28.4 & 30.3 & 29.1 \\
\hline Leucocitos $\left(\mathrm{mm}^{3}\right)$ & 1,900 & 1,500 & 2,200 & 2,800 \\
\hline Neutrófilos $\left(\mathrm{mm}^{3}\right)$ & 1,178 & 900 & 1,496 & 2,240 \\
\hline Linfocitos $\left(\mathrm{mm}^{3}\right)$ & 627 & 600 & 704 & 364 \\
\hline Plaquetas $\left(\mathrm{mm}^{3}\right)$ & 97,200 & 86,200 & 110,000 & 207,000 \\
\hline Creatinina (mg/dL) & & 0.6 & 0.5 & 0.4 \\
\hline Nitrógeno ureico (mg/dL) & & 5.9 & & 8.0 \\
\hline Sodio $(\mathrm{mmol} / \mathrm{L})$ & & 137 & & 133 \\
\hline AST (U/L) & 58 & 49 & 73 & 207 \\
\hline ALT (U/L) & 65 & 44 & 49 & 167 \\
\hline $\mathrm{TP}(\mathrm{s})$ & & 14 & & 12.9 \\
\hline TPT (s) & & 29.8 & & 30.8 \\
\hline
\end{tabular}

Estudio de líquido cefalorraquídeo

- Citoquímico

- Coloración de Gram

- Baciloscopia

- $\mathrm{KOH}$

- Cultivos para gérmenes aerobios, micosis profundas y micobacterias

- PCR para leptospira

- FilmArray ${ }^{\circledR}$ meningitis/encefalitis

Hemocultivos aerobios (\#2)

IgG/IgM Rickettsia (inmunofluorescencia indirecta)

Dengue (ELISA)

IgM/lgG leptospira (inmunofluorescencia indirecta)

Cultivo leptospira en orina

PCR Ehrlichia spp. en sangre total

Gota gruesa día 1, 9, 11 de enfermedad

IgM virus Epstein-Barr

IgM citomegalovirus

Cultivo para leptospira en orina

Extendido de sangre periférica
Aspecto: transparente

Glucosa: $36 \mathrm{mg} / \mathrm{dL}$

Proteínas: $47.7 \mathrm{mg} / \mathrm{dL}$

Leucocitos: $20 / \mathrm{mm}^{3}$

Neutrófilos: $16 \%$

linfocitos: $84 \%$

No se observan bacterias

Escasa reacción leucocitaria

Negativa

No se observan estructuras micóticas

Negativos

Negativa

Negativo

Negativos

Negativa en fase aguda y de convalecencia

NS1: negativo

IgM: negativo

IgG: positiva

Negativo

Negativo

Positiva

Negativas

No reactiva

No reactiva

Negativo

No se observan mórulas

AST = aspartato aminotransferasa; $\mathrm{ALT}$ = alanina transaminasa; $\mathrm{TP}$ = tiempo de protrombina; $\mathrm{TPT}$ = tiempo parcial de tromboplastina; $\mathrm{KOH}=$ hidróxido de potasio 
Rev Latin Infect Pediatr. 2021; 34 (1): 41-47

de una muestra de sangre total anticoagulada con EDTA almacenada en refrigeración. Una alícuota de $200 \mu \mathrm{L}$ de la muestra fue sometida a extracción de ADN por medio de columnas de afinidad, utilizando un estuche de la casa comercial QIAGEN (DNeasy ${ }^{\circledR}$ Blood \& Tissue kit) siguiendo las instrucciones del fabricante. La amplificación de un fragmento de ADN correspondiente a 16S rRNA de Ehrlichia spp. fue realizada mediante $\mathrm{PCR}$ a tiempo real, siguiendo un protocolo validado por el laboratorio del Instituto Colombiano de Medicina Tropical, con un límite de detección de 10 copias/ $\mu \mathrm{L}$ y la capacidad para detectar E. canis, E. ewingii, E. chaffeensis en la misma reacción. Una mezcla de PCR fue preparada con 400 pmol de cada iniciador y 200 pmol de una sonda específica marcada con FAM en un volumen final de $12.5 \mu \mathrm{L}$, por duplicado. La amplificación fue realizada en un termociclador Rotor Gene 6000, con una desnaturalización inicial de 15 minutos a $95{ }^{\circ} \mathrm{C}$ seguida de 40 ciclos: 15 segundos a $95^{\circ} \mathrm{C}$ y 45 segundos a $60{ }^{\circ} \mathrm{C}$ se detectó fluorescencia $y$ el umbral (threshold) fue ajustado en 0.05 . Se obtuvo amplificación y detección de un producto correspondiente al blanco molecular 16S rRNA de Ehrlichia spp. (E. canis, E. ewingii, E. chaffeensis) en la muestra analizada $(\mathrm{Ct}=31.6)$.

\section{DISCUSIÓN}

La erliquiosis es una zoonosis transmitida por la picadura de garrapatas de perros y venados, reconocida como enfermedad en humanos desde 1986. Esta entidad se relaciona con factores ambientales asociados a la pobreza, el hacinamiento y la falta de higiene. , $^{2,3}$

El agente etiológico es una bacteria en forma de coco, Gram negativa, que mide entre 0.5 a 1 micra de diámetro con tropismo por monocitos y granulocitos. Pertenece a la familia Anaplasmataceae, de la cual hacen parte cuatro géneros: Ehrlichia, Anaplasma, Neorickettsia, Candidatus neoehrlichia, este último es un nuevo género propuesto. ${ }^{4}$

Dentro de las especies que hacen parte del género Ehrlichia y que causan enfermedad en el hombre se encuentran: E. chaffeensis, E. ewingii, E. canis, E. muris, E. ruminantium, E. mineirensis. Cada especie infecta a una célula blanca específica: $E$. chaffeensis afecta a los monocitos/macrófagos causando erliquiosis monocítica humana (EMH) y E. ewingii afecta a los granulocitos causando erliquiosis humana ewingii (EHE). ${ }^{5}$ Son transmitidas por diferentes especies de garrapatas. Amblyomma americanum, también conocida como garrapata estrella solitaria, cuyos hospederos naturales son el perro y el venado de cola blanca, es responsable de la transmisión de E. chaffeensis y E. ewingii, geográficamente se distribuye en Estados Unidos (EU) y América del Sur.'

En algunas publicaciones se menciona transmisión a través de trasplante de órgano sólido y transfusión de hemoderivados; principalmente por el género Anaplasma, debido a que la bacteria sobrevive en eritrocitos congelados hasta por 18 días. ${ }^{6}$

Desde 1986, año en que se describió el primer caso de erliquiosis en Estados Unidos hasta 2005, los casos notificados por los CDC eran aproximadamente $480 .{ }^{5}$ Hacia el año 2016 se considera que en Estados Unidos la incidencia anual es de 6.4 por 1 millón de habitantes. ${ }^{6}$ Se presenta con mayor frecuencia en el sexo masculino y mayores de 40 años (61\%). Datos de seroprevalencia indican que puede ser común en niños, hasta $20 \%$, a pesar de no haber presentado sintomatología. ${ }^{4,7}$ Resultados de estudios prospectivos de seroprevalencia en 2,000 niños en siete centros académicos en el sur este y centro de los Estados Unidos revelaron que el 13\% tenían anticuerpos para Ehrlichia chaffeensis con títulos de 1:80 y $3 \%$ con títulos de $1: 160{ }^{3}$

En América del Sur, estudios de seroprevalencia en dueños de caninos domésticos con erliquiosis reportan serología positiva en $1.2 \%$ en Brasil, $14.3 \%$ en Argentina, $10.5 \%$ en Chile y $30 \%$ en Venezuela. ${ }^{9}$

Ríos y colaboradores realizaron un estudio descriptivo, prospectivo de cohorte transversal en el que estudiaron la presencia de anticuerpos séricos tipo IgM por técnica de inmunofluorescencia indirecta (IFI) en trabajadores del campo del departamento de Sucre, Colombia, encontrándose una prevalencia de $3.3 \%$ en ordeñadores y jornaleros. ${ }^{3}$

El primer caso de erliquiosis en Colombia se publicó en 2014 por Hidrón y colaboradores, se trata de un hombre de 19 años, residente en la costa pacífica colombiana, militar, quien se presentó con fiebre, falla respiratoria, insuficiencia renal y coagulopatía, se le hizo el diagnóstico por serología ( $\lg M 1: 160)$. También tenía antecedente de contacto con varios animales, incluyendo perros, como en el caso descrito. ${ }^{2}$

Se ha descrito que la mortalidad oscila entre $1 \mathrm{a}$ $3 \%$ y aumenta hasta $17 \%$ en pacientes inmunocomprometidos. ${ }^{4}$

La enfermedad inicia con la picadura de una garrapata infectada, seguida de la replicación de la 
Rev Latin Infect Pediatr. 2021; 34 (1): 41-47

bacteria en los glóbulos blancos (monocitos/macrófagos en caso de E. chaffeensis y granulocitos en caso de E. ewingii), posteriormente se forman mórulas en el interior de las células que se rompen hacia el exterior, liberando miles de bacterias en plasma que infectan más células sanas. ${ }^{8}$

Ehrlichia spp. es capaz de inhibir parcialmente la respuesta inmune innata, aumentando la expresión de factores antiapoptóticos y disminuyendo la expresión de citoquinas TH1 (interleucinas 12, 18), evitando así la activación de monocitos.

Los hallazgos histopatológicos frecuentes incluyen formación de granulomas, hiperplasia mieloide y megacariocitosis en la médula ósea. Algunos pacientes desarrollan eritrofagocitosis y plasmocitosis. También se describen necrosis hepatocelular, granulomas hepáticos, colestasis, hiperplasia difusa de fagocitos mononucleares del bazo, hígado, ganglios linfáticos y médula ósea; infiltrados linfohistiocíticos perivasculares de varios órganos incluyendo riñón, corazón, hígado, meninges y cerebro. ${ }^{7}$ Todo lo anterior explica los hallazgos clínicos de la paciente: pancitopenia, elevación de transaminasas y meningitis.

La fiebre es el síntoma más frecuente (97\%), le siguen en frecuencia: cefalea (80\%), escalofríos (61\%), malestar general (84\%), mialgias (57\%), artralgias (41\%); síntomas gastrointestinales: náuseas, vómito, diarrea (41\%), tos (26\%), meningitis o meningoencefalitis, convulsiones y coma (20\%), la erupción en la piel puede ser maculopapular, petequial o una eritrodermia difusa que respeta palmas, plantas y cara y ocurre en $66 \%$ de los niños y $21 \%$ en adultos. ${ }^{3,7}$ Todos estos hallazgos se encontraron en la paciente que se describe, excepto la tos, los síntomas gastrointestinales y el coma.

Las complicaciones son infrecuentes, pero pueden manifestarse durante la enfermedad aguda, algunos días después del inicio o más tardíamente y permanecer por largos periodos de tiempo aun sin infección activa. Entre ellas se han descrito: falla cardiovascular, meningitis aséptica, hemorragias, insuficiencia o falla hepática, neumonía intersticial, SDRA (síndrome de dificultad respiratoria aguda), miocarditis, síndrome hemofagocítico. 5,7,10,11

La afectación del sistema nervioso central (SNC) se identifica en aproximadamente el $20 \%$ de los pacientes con erliquiosis y en algunos casos puede estar asociado con convulsiones y coma. Las secuelas neurológicas a largo plazo en niños son poco comunes, pero incluyen retraso cognitivo y deterioro de la motricidad fina. ${ }^{7}$ En este caso, la paciente presentó meningitis, como complicación aguda; sin embargo, no tuvo secuelas neurológicas.

Para el diagnóstico se deben tener en cuenta los antecedentes epidemiológicos que pueden dar la clave para sospechar la enfermedad e iniciar tratamiento oportuno, así como ocurrió con este caso, quien tuvo contacto con perros infestados por garrapatas y enfermos con síntomas compatibles con erliquiosis canina: fiebre (ocasionalmente hipotermia en perros pancitopénicos), letargia, anorexia, linfadenomegalia, esplenomegalia, palidez de las mucosas, anomalías oculares y hemorragias.

Dentro de los hallazgos de laboratorio se encuentran: linfopenia (70\%) y trombocitopenia (90\%), las dos tienen su nadir en la primera semana de la enfermedad, anemia (50\%), hiponatremia (70\%), transaminitis (90\%), alteraciones del LCR con: pleocitosis, hipoglucorraquia e hiperproteinorraquia. Todas estas alteraciones de laboratorio se presentaron en el caso descrito.

En el extendido de sangre periférica, médula ósea y LCR se pueden observar las mórulas (agregados o microcolonias bacterianas), utilizando técnicas como Giemsa o Wright; este método tiene mejor sensibilidad durante la primera semana de la enfermedad. Las mórulas se detectan dentro de los monocitos en aproximadamente $3 \%$ de los pacientes con erliquiosis humana. Por el contrario, en los casos de anaplasmosis se pueden ver en el 25 al $75 \%$ de los pacientes. ${ }^{7}$ Esta es la razón por la que en nuestro paciente no se detectaron mórulas en el extendido.

Los métodos serológicos tienen una alta tasa de reacción cruzada con el género Anaplasma lo que puede generar falsos positivos, se considera positivo un solo título de inmunoglobulina $G \geq 1: 256$ o seroconversión con título mínimo de 1:64. La técnica recomendada es IFI con aumento de cuatro veces los títulos de anticuerpos IgG tomados en fase aguda y en fase de convalecencia. Durante la primera semana de la enfermedad, la sensibilidad de este método varía entre 20 a $55 \%$, aumentando hacia la tercera semana hasta un $90 \%$.

La realización del cultivo no se recomienda en la práctica clínica, debido al crecimiento lento de esta bacteria; su utilización se reserva para la práctica experimental en el laboratorio.

Otro método diagnóstico es la inmunohistoquímica en médula ósea, su sensibilidad disminuye después 
del inicio de la terapia antibiótica o después de las primeras 48 horas de la enfermedad.

La PCR se ha convertido en la prueba de elección para confirmar el diagnóstico de esta infección, debido a su alta especificidad (60-85\%) y sensibilidad (60-85\% para E. chaffeensis y $67-90 \%$ para A. phagocytophilum), así como a su rapidez. La PCR es la única prueba de diagnóstico definitiva para la infección por $E$. ewingii, ya que ésta no es cultivable. Se han descrito pruebas múltiples capaces de detectar varios agentes etiológicos relacionados, como la que se utilizó para hacer el diagnóstico en nuestro caso que tiene la capacidad de detectar tres especies: E. canis, E. ewingii, E. chaffeensis. La PCR en sangre total está disponible comercialmente y permite un diagnóstico rápido de infección hasta en un $85 \%$ de los casos. Esta prueba tiene mayor sensibilidad en la primera semana de la enfermedad y puede disminuir después de iniciada la doxiciclina; es particularmente importante para la detección de la infección en etapas tempranas cuando los niveles de anticuerpos son muy bajos o indetectables. Puede realizarse en LCR, aunque la sensibilidad es inferior que en sangre, probablemente debido a un volumen significativamente menor de células infectadas. ${ }^{4,5,7}$

La definición de caso de erliquiosis según los CDC es la siguiente:

1. Fiebre indiferenciada y al menos uno de los siguientes:

a. PCR positiva en sangre o tejidos.

b. Incremento de cuatro veces los títulos de lgG pareados con cuatro semanas de diferencia (fase aguda y de convalecencia).

c. Demostración del microorganismo en sangre periférica o tejidos. ${ }^{8}$

Por lo tanto, el caso que se presenta es un caso confirmado de erliquiosis humana.

Debido a que los síntomas son inespecíficos, los diagnósticos diferenciales a considerar son múltiples, incluyendo otras infecciones transmitidas por garrapatas: rickettsiosis, fiebre recurrente, tularemia, babesiosis y otras enfermedades como leptospirosis, hepatitis virales, dengue, fiebre tifoidea, salmonelosis y endocarditis, entre otras. ${ }^{2}$

El tratamiento se debe instaurar de forma temprana ante la sospecha clínica, no se deben esperar resultados de pruebas confirmatorias. Se propone el uso de doxiciclina para todas las edades durante siete días y si hay compromiso del sistema nervioso central se puede extender hasta 14 . En pacientes con historia de hipersensibilidad y durante el embarazo se puede dar rifampicina como alternativa.

La mayoría de los casos presentan mejoría parcial de los síntomas en las primeras 24 horas de iniciado el tratamiento y mejoría significativa a las 72 horas; de lo contrario se debe reevaluar el diagnóstico.

Hamburg y colaboradores, en un estudio de cohorte retrospectiva de 46 casos de erliquiosis, compararon el desenlace de pacientes diagnosticados por PCR, cuando se administraba tempranamente doxiciclina (primeras 24 horas vs posterior a las 24 horas) encontrando que los pacientes con tratamiento temprano tenían mejor evolución. ${ }^{11}$

El pronóstico de esta entidad es variable, algunos pacientes presentan secuelas neurológicas como retraso cognitivo, alteración de la motricidad fina, neuropatía periférica.

No se recomienda ningún tipo de aislamiento específico, sólo se requieren precauciones estándar, tampoco se recomienda profilaxis postpicadura pues no se ha comprobado su eficacia. ${ }^{4}$

\section{CONCLUSIÓN}

La erliquiosis humana es una zoonosis transmitida por garrapatas que está siendo descrita con mayor frecuencia en pacientes de todas las edades. Se debe sospechar en un paciente febril, con antecedente de picadura por garrapatas y hallazgos como leucopenia, trombocitopenia y transaminasas elevadas. En estos casos, el tratamiento con doxiciclina se debe iniciar de forma inmediata para mejorar el pronóstico.

\section{REFERENCIAS}

1. Ismail N, Bloch KC, McBride JW. Human ehrlichiosis and anaplasmosis. Clin Laborat Med. 2010; 30 (1): 261-292.

2. Hidrón Botero A, Muñoz Ramírez F, Vega Miranda J. Primer caso de ehrlichiosis monocítica humana reportado en Colombia. Infectio. 2014; 18 (4): 162-166.

3. Ríos R, Franco S, Mattar S, Urrea M, Tique V. Seroprevalence of Leptospira sp., Rickettsia sp. and Ehrlichia $s p$. in rural workers of Sucre, Colombia. Infectio. 2008; 12 (2): 90-95.

4. American Academy of Pediatrics. Human ehrlichiosis, anaplasmosis, and related infections attributable to bacteria in the family Anaplasmataceae. In: Kimberlin DW, Brady MT, Jackson MA, Long SS, eds. Red book: 2018-2021 report of the committee on infectious diseases. 31st ed. Itasca, IL: American Academy of Pediatrics; 2018-2021. pp. 323-327. 
Rev Latin Infect Pediatr. 2021; 34 (1): 41-47

5. Dumler JS, Madigan JE, Pusterla N, Bakken JS. Ehrlichioses in humans: epidemiology, clinical presentation, diagnosis, and treatment. Clin Infect Dis. 2007; 45 (Supplement 1): S45-S51.

6. Biggs HM. Diagnosis and management of tickborne rickettsial diseases: rocky mountain spotted fever and other spotted fever group rickettsioses, ehrlichioses, and anaplasmosis-United States. MMWR Recomm Rep [Internet]. 2016 [citado 7 de abril de 2020]; 65. Disponible en: https://www.cdc.gov/mmwr/volumes/65/rr/rr6502a1.htm

7. Ismail N, McBride JW. Tick-borne emerging infections. Clinics in Laboratory Medicine. 2017; 37 (2): 317-340.

8. Lantos P, Krause PJ. Ehrlichiosis in children. Semin Pediatr Infect Dis. 2002; 13 (4): 249-256.

9. Barrios AL, Lí EO, Suárez AF, Manchego SA, Hoyos SL. Evidencia hematológica y serológica de Ehrlichia spp en propietarios de caninos domésticos con antecedentes de ehrlichiosis en Lima metropolitana. Rev Investig Vet Perú. 2013; 24 (1): 64-71.

10. Otrock ZK, Eby CS, Burnham CD. Human ehrlichiosis at a tertiary-care academic medical center: Clinical associations and outcomes of transplant patients and patients with hemophagocytic lymphohistiocytosis. Blood Cells Mol Dis. 2019; 77: 17-22.

11. Hamburg BJ, Storch GA, Micek ST, Kollef MH. The importance of early treatment with doxycycline in human ehrlichiosis. Medicine. 2008; 87 (2): 53-60.

Correspondencia:

Alixandra De la Espriella Pérez

Calle 78b No. 69-240,

Medellín, Antioquia.

Teléfono: (574) 4459387

E-mail: alixandradelaespriella2@hotmail.com 